\title{
Medical students' perspectives of their clinical comfort and curriculum for acute pain management
}

\author{
Uyen Evelyn Tran' \\ Janeva Kircher ${ }^{2,3}$ \\ Priya Jaggi ${ }^{2}$ \\ Hollis Lai' \\ Tracey Hillier ${ }^{1,4}$ \\ Samina $\mathrm{Ali}^{3,5}$ \\ 'Undergraduate Medical Education, \\ Faculty of Medicine and Dentistry, \\ University of Alberta, Edmonton, \\ Alberta, Canada; ${ }^{2}$ Department of \\ Emergency Medicine, Faculty of \\ Medicine and Dentistry, University of \\ Alberta, Edmonton, Alberta, Canada; \\ ${ }^{3}$ Department of Pediatrics, Faculty of \\ Medicine and Dentistry, University \\ of Alberta, Edmonton, Alberta, \\ Canada; ${ }^{4}$ Department of Radiology \\ \& Diagnostic Imaging, University of \\ Alberta, Edmonton, Alberta, Canada; \\ ${ }^{5}$ Women and Children's Health \\ Research Institute, Edmonton, \\ Alberta, Canada
}

This article was published in the following Dove Press journal: Journal of Pain Research

\begin{abstract}
Objectives: Acute pain is a common presenting complaint in health care. Yet, undertreatment of pain remains a prevailing issue that often results in poor short- and long-term patient outcomes. To address this problem, initiatives to improve teaching on pain management need to begin in medical school. In this study, we aimed to describe medical students' perspectives of their curriculum, comfort levels, and most effective pain teaching modalities.
\end{abstract}

Materials and methods: A cross-sectional, online survey was distributed to medical students at the University of Alberta (Edmonton, Canada) from late May to early July 2015. Data were collected from pre-clerkship (year 1 and 2) and clerkship (year 3 and 4) medical students for demographic characteristics, knowledge, comfort, and attitudes regarding acute pain management. Results: A total of 124/670 (19.6\%) surveys were returned. Students recalled a median of 2 (interquartile range $[\mathrm{IQR}]=4), 5(\mathrm{IQR}=3.75), 4(\mathrm{IQR}=8)$, and $3(\mathrm{IQR}=3.75)$ hours of formal pain education from first to forth year, respectively. Clerkship students were more comfortable than pre-clerks with treating adult pain $(52.1 \%$ of pre-clerks "uncomfortable" versus $22.9 \%$ of clerks, $p<0.001$ ), and overall, the majority of students were uncomfortable with managing pediatric pain (87.6\% [64/73] pre-clerks and 75.0\% [36/48] clerks were "uncomfortable"). For delivery of pain-related education, the majority of pre-clerks reported lectures as most effective $(51.7 \%)$, whereas clerks chose bedside instruction (43.7\%) and small group sessions (23.9\%). Notably, $54.2 \%, 39.6 \%$, and $56.2 \%$ of clerks reported incorrect doses of acetaminophen, ibuprofen, and morphine, respectively, for adults. For children, $54.2 \%, 54.2 \%$, and $78.7 \%$ of clerks reported incorrect doses for these same medications.

Conclusion: Medical students recall few hours of training in pain management and report discomfort in treating and assessing both adult and (more so) pediatric pain. Strategies are needed to improve education for future physicians regarding pain management.

Keywords: analgesia, undergraduate, curriculum, medical education, survey

\section{Introduction}

Oligoanalgesia, the undertreatment of pain, is a recognized problem and can have numerous detrimental effects for patients of all ages. ${ }^{1}$ In adults, inadequately treated pain can compromise sleep and physical functions, increase health care costs, and is a common reason for patients to return to hospital after discharge. ${ }^{2-5}$ In children, it can increase length of stay and cause slow healing as well as emotional trauma and suffering. ${ }^{1}$ This can, in turn, lead to persistent fear of medical events or health care consultations, avoidance or overuse of medical care, and heightened sensitivity to subsequent medical care. ${ }^{2-6}$ In fact, in light of the high prevalence and potential harm, the
Correspondence: Samina Ali

Department of Pediatrics, , Faculty of Medicine and Dentistry, University of Alberta, 3-583 Edmonton Clinic Health Academy, I I405-87 Avenue, Edmonton, Alberta T6G IC9, Canada

Tel +l 7802485575

Fax +I 8887758876

Email sali@ualberta.ca 
World Health Organization has suggested that pain treatment is a public health concern of major significance. ${ }^{7}$

Undertreatment of pain is a well-documented problem for children, ${ }^{8-10}$ as only two-thirds of children in pain have been shown to receive analgesia, both in the emergency department and inpatient settings. ${ }^{8,9}$ Several hypotheses exist to explain this finding, including physician's lack of comfort with medication dosing and adverse effects, the belief that children do not feel pain like adults and/or will not remember it, the inability of young children to verbalize their needs, potential for opioid dependency, risk of oversedation, and lack of guidelines. ${ }^{11,12}$ Pediatric pain management education in medical school has been shown to improve knowledge, confidence, attitudes, and self-reported skills. ${ }^{13-15}$ However, within most medical school pain curricula, a stronger focus is placed on adult pain management ${ }^{16}$ and little is known about the medical students' understanding of pediatric pain management and assessment.

Previous studies have shown that educational initiatives aimed at improving health care providers' knowledge of pain management and decrease pain experience for patients. ${ }^{17}$ Thus, there have been calls to increase and standardize the undergraduate medical pain curriculum ${ }^{18}$ as a means of addressing inadequate pain management by practicing physicians. ${ }^{1,5,19}$ This study is especially timely, as 2018 has been identified as the global year for excellence in pain education by the International Association for the Study of Pain. ${ }^{20}$ Overall, while $80 \%$ of US schools and $92 \%$ of Canadian schools mandate pain education sessions, significant variation in pain curricula throughout US and Canadian medical schools exists. ${ }^{16}$ Further, rather than providing a dedicated block, the undergraduate medical school pain curriculum is often fragmented and taught as small components spread out over multiple core courses. ${ }^{16}$

Previous studies have identified themes in pain education and areas of the pain curriculum that may be lacking adequate coverage in medical school, including oncologic pain, pediatric pain, geriatric pain, risks of opioid use, and medicolegal consequences of pain treatment. ${ }^{16,18}$ However, to our knowledge, no research has assessed the medical students' perspectives on their own curriculum or their knowledge of pain management, especially in the acute care setting. Additionally, none have explored the differences between years 1 and 2 (pre-clerkship) and years 3 and 4 (clerkship) medical students who have varying levels of clinical exposure and may require different styles of teaching.

The purpose of our study was to evaluate medical students' perceptions of acute, non-oncologic pain management in both adults and children and the delivery of this in their medical education. Our study objectives were to describe current medical training received in acute pain management, evaluate students' knowledge of pain assessment techniques and analgesics, and gauge their level of comfort in assessing and treating acute pain. Furthermore, we wanted to determine what they perceived were facilitators and barriers of optimal pain management.

\section{Materials and methods Study design and participants}

All medical students $(n=670)$ enrolled at the University of Alberta (Edmonton, Canada) were identified through the undergraduate medical education listserv, an application used to distribute information to a list of subscribers through electronic mail. Students were invited to complete an online survey through MedSIS, a secure electronic platform utilized by the University of Alberta medical school for course and grade management. The electronic survey was administered using a modified Dillman ${ }^{21}$ approach over a 3-month study period. An introduction letter including a link to the survey was sent on day 0 . Reminders were sent on days 14 and 30 and the survey was closed on day 60 . The survey period took place between late May and early July. Consent was implicit in completion of the survey; respondents were able to skip any questions that they wished. As a quality improvement initiative, this study was deemed exempt from ethics review by the University of Alberta Health Research Ethics Board.

\section{Survey tool development}

A novel survey tool was created, as no appropriate tool existed in the literature. ${ }^{6}$ The survey was developed in accordance with currently published guidelines. ${ }^{22}$ An expert panel of five individuals representing adult medicine, pediatric medicine, and medical education informed survey development. The survey was piloted with a group of five medical students to ensure face validity and sensibility of the questions. ${ }^{23}$

Survey themes consisted of demographic characteristics (e.g., age, sex, year of training), knowledge, comfort, and attitudes regarding acute pain management. Knowledge questions included a recall of curriculum dedicated to pain assessment and management, the students' preferred modality for learning, and dosing of common analgesics for pediatric and adult patients. Comfort questions concerned students' pain assessment and treatment. Finally, students were also asked to rate their agreement with a series of pain management myths or statements (e.g., "children require less analgesia than adults as they will not remember the pain"), on a 
five-point Likert scale, ranging from "strongly disagree" to "strongly agree".

\section{Data analysis}

Survey responses were collated and stratified by year of medical school: pre-clerkship (years 1 and 2) versus clerkship (years 3 and 4). Median scores and interquartile ranges (IQRs) were determined for continuous variables: comfort level with pain management, perceived importance and prioritization of pain management, and comfort with determining pain severity. Mann-Whitney tests for two-sample, unpaired comparisons were used to assess pre-clerkship and clerkship response differences, with an alpha level of 0.05 to determine statistical significance. Frequency distributions summarized the categorical variables (e.g., sex, year of medical school). Associations between sex and comfort level were also explored. Additionally, associations between hours of instruction and students' comfort in pain assessment, pain management, prescribing medication, and dosing of common pain medication were investigated.

\section{Results}

\section{Demographic characteristics}

A total of $124 / 670(19.6 \%)$ students completed the survey during the study period. Three were excluded from comparative analysis as their year of medical school was not indicated, resulting in 121 analyzed surveys; 73/121 (60.3\%) of the respondents were pre-clerks and 48/121 (39.7\%) were clerks. The majority of pre-clerks $(87 \%)$ were between 19 and 25 years of age and half of the clerks (50\%) were between 26 and 30 years of age (Table 1 ). In the month before completing

Table I Medical student demographics $(\mathrm{N}=|2|)$

\begin{tabular}{|c|c|c|c|}
\hline $\begin{array}{l}\text { Demographic } \\
\text { variables }\end{array}$ & $\begin{array}{l}\text { Pre-clerkship } \\
\text { (years I, 2), } \\
\text { n=73, n (\%) }\end{array}$ & $\begin{array}{l}\text { Clerkship } \\
\text { (years 3, 4), } \\
n=48, n(\%)\end{array}$ & $\begin{array}{l}\text { Overall, } \\
N=12 \text { I, } \\
\text { n (\%) }\end{array}$ \\
\hline \multicolumn{4}{|l|}{ Age } \\
\hline $19-25$ years & $62(84.9)$ & $23(47.9)$ & $85(70.2)$ \\
\hline $26-30$ years & $7(9.6)$ & $24(50.0)$ & $31(25.6)$ \\
\hline$>30$ years & $2(2.7)$ & $0(0.0)$ & $2(1.7)$ \\
\hline Missing responses & $2(2.7)$ & $I(2.1)$ & $3(2.5)$ \\
\hline \multicolumn{4}{|l|}{ Sex } \\
\hline Male & $4 \mathrm{I}(56.2)$ & $24(50.0)$ & $65(53.7)$ \\
\hline Female & $32(43.8)$ & $22(45.8)$ & $54(44.6)$ \\
\hline Missing responses & $0(0.0)$ & $2(4.2)$ & $2(1.7)$ \\
\hline $\begin{array}{l}\text { Utilization of pain } \\
\text { medications for }>7 \text { days in } \\
\text { the last month (respondents } \\
\text { or a close family member/ } \\
\text { friend) }\end{array}$ & 21 (28.8) & $10(20.8)$ & $31(25.6)$ \\
\hline
\end{tabular}

the survey, a total of $31 / 121(25.6 \%)$ of the students, of whom $21 / 121(17.3 \%)$ were pre-clerks and 10/121 (8.3\%) were clerks, had $>7$ days of personal experience using pain medications for themselves or for a close family member or friend (Table 1).

\section{Knowledge}

\section{Current curriculum and students' preferences for delivery of pain education}

Students recalled a median of $2(\mathrm{IQR}=4), 5(\mathrm{IQR}=3.75), 4$ $(\mathrm{IQR}=8)$, and $3(\mathrm{IQR}=3.75)$ total hours of formal pain education from first to fourth year, respectively. Students from all 4 years felt that the primary method of delivering education on pain management in medical school was in lecture format. According to student responses, $70.3 \%$ and $47.4 \%$ of the preclerkship and clerkship curriculum, respectively, consisted of lectures. As lectures comprised a smaller proportion of clerkship curriculum, clerks received more training in the form of bedside teaching (33.3\%) than pre-clerks (12.1\%). Small group sessions were also utilized and comprised $\sim 14 \%$ of teaching for both groups. All students recalled being taught several pain assessment scales, including the Verbal Numerical Scale (118/121 students; 98\%), Faces Pain Scale (87/121; 72\%), visual analog scale (VAS; 68/121; 56\%), and Faces, Legs, Activity, Cry, Consolability scale (8/121, $6.6 \%$; Table 2).

A large proportion of students, $56.9 \%$ (41/72) of preclerks and $58.6 \%(27 / 46)$ of clerks, reported that there was no time devoted to pediatric pain in their curriculum. The remaining students recalled that the curriculum included $1 \%-25 \%$ of pediatric pain teaching (Table 2). Our data show that for the first 2 years of medical school, lectures $(84.1 \%)$ were primarily used to deliver pediatric-specific instruction, whereas bedside teaching (41.7\%) and lectures (38.9\%) were the main teaching formats in clerkship (Table 2).

Overall, while pre-clerkship students thought lecture was the most effective way to have their acute pain education delivered $(45 / 66 ; 51.7 \%)$, clerkship students felt that bedside teaching $(31 / 38 ; 43.7 \%)$ was more effective (Table 2$)$. As the curriculum at the University of Alberta Medical School was divided into blocks during pre-clerkship and rotations during clerkship, students were asked which block or clinical rotation they felt was the best in delivering teaching on acute pain management. Blocks are 6-14-week periods within a school year that are allotted to cover medical knowledge of different body systems. Pre-clerkship students reported that the top three blocks in which they received the most pain teaching were introduction to the profession (19/81), oncology (15/81), 
Table 2 Medical students' recollection of their pain curriculum $(\mathrm{N}=|2|)$

\begin{tabular}{|c|c|c|}
\hline Training variables & $\begin{array}{l}\text { Pre-clerkship } \\
\text { (years I, 2) }\end{array}$ & $\begin{array}{l}\text { Clerkship } \\
\text { (years 3, 4) }\end{array}$ \\
\hline \multicolumn{3}{|l|}{ Hours of pain education } \\
\hline Year I $(n=4 I)$ & $2(\mathrm{IQR}=4)$ & \\
\hline Year $2(n=28)$ & $5(\mathrm{IQR}=3.75)$ & \\
\hline Year $3(n=26)$ & & $4(\mathrm{IQR}=8)$ \\
\hline Year $4(n=20)$ & & $3(\mathrm{IQR}=3.75)$ \\
\hline \multicolumn{3}{|l|}{ Type of training received } \\
\hline Adult pain management & $n(\%), n=69$ & $n(\%), n=47$ \\
\hline Lecture & $64(70.3)$ & $37(47.4)$ \\
\hline Bedside & $11(12.1)$ & $26(33.3)$ \\
\hline Small group & $13(14.3)$ & $11(14.1)$ \\
\hline Other & $3(3.3)$ & $4(5.1)$ \\
\hline Pediatric pain management & $n(\%), n=42$ & $n(\%), n=35$ \\
\hline Lecture & $37(84.1)$ & $14(38.9)$ \\
\hline Bedside & I (2.3) & $15(41.7)$ \\
\hline Small group & $4(9.1)$ & $6(16.7)$ \\
\hline Other & $2(4.5)$ & $\mathrm{I}(2.8)$ \\
\hline Non-respondents & $31(73.8)$ & $19(54.3)$ \\
\hline Type of training preferred & $n(\%), n=66$ & $n(\%), n=48$ \\
\hline Lecture & $45(51.7)$ & $16(22.5)$ \\
\hline Bedside & $21(24.1)$ & $31(43.7)$ \\
\hline Small group & $16(18.4)$ & $17(23.9)$ \\
\hline Other & $5(5.7)$ & $6(8.5)$ \\
\hline Non-respondents & 7 & 1 \\
\hline Pain assessment scales taught & $n(\%), n=73$ & $n(\%), n=48$ \\
\hline Numerical Scale & $71(44.1)$ & $47(38.8)$ \\
\hline VAS & $39(24.2)$ & $29(24.0)$ \\
\hline Faces Pain Scale & $48(29.8)$ & $39(32.2)$ \\
\hline FLACC Scale & $3(1.9)$ & $5(4.1)$ \\
\hline Other & $0(0.0)$ & $\mathrm{I}(0.83)$ \\
\hline $\begin{array}{l}\text { Pediatric pain education ( } \% \text { of } \\
\text { total pain curriculum) }\end{array}$ & $n(\%), n=72$ & $n(\%), n=46$ \\
\hline $0 \%$ & $4 \mathrm{I}(57)$ & $27(59)$ \\
\hline $1 \%-25 \%$ & $31(43)$ & $19(4 I)$ \\
\hline $26 \%-50 \%$ & $0(0.0)$ & $0(0.0)$ \\
\hline $51 \%-75 \%$ & $0(0.0)$ & $0(0.0)$ \\
\hline $76 \%-100 \%$ & $0(0.0)$ & $0(0.0)$ \\
\hline
\end{tabular}

Abbreviations: FLACC, Faces, Legs, Activity, Cry, Consolability; IQR, interquartile range; VAS, visual analog scale.

and musculoskeletal system (8/81). Clerkship students thought that the oncology (15/47) and musculoskeletal system (6/47) blocks, palliative care electives (5/47), and internal medicine rotations $(5 / 47)$ provided the best pain treatment instruction.

\section{Perceived importance and actual emphasis on teaching of acute pain management}

We asked students if they felt treatment of acute pain was important and pre-clerkship students responded with a median of $90 / 100 \mathrm{~mm}$ on a VAS (IQR=20), where $0 \mathrm{~mm}$ was "very unimportant" and $100 \mathrm{~mm}$ was "very important".
Likewise, clerks gave a rating of 95/100 $\mathrm{mm}(\mathrm{IQR}=14)$ on the same scale. However, when asked about the degree at which pain education was prioritized in the overall medical curriculum, both pre-clerkship and clerkship students reported a median rating of $32 / 100 \mathrm{~mm}$ (IQR=35 and 31 , respectively).

\section{Comfort}

Comfort with pain assessment and treatment in preclerkship and clerkship

On a similar VAS where $0 \mathrm{~mm}$ was "very uncomfortable" and $100 \mathrm{~mm}$ "very comfortable", clerks $(\mathrm{n}=48)$ were more comfortable than pre-clerks with determining pain severity in adults (75 mm [IQR 34] versus $50 \mathrm{~mm}$ [IQR 42], $p<0.001$ ) and children (30 mm [IQR 31] versus $21 \mathrm{~mm}$ [IQR 31], $p=0.03)$ than pre-clerks $(\mathrm{n}=73)$, although both were more comfortable with adult patients. In fact, $75.0 \%$ (36/48) of clerks felt unable to accurately assess children's pain (VAS $<50 \mathrm{~mm}$; Figure 1A).

Pre-clerkship students reported less comfort with treating adult pain compared to clerks (pre-clerks rated their comfort level at $25 \mathrm{~mm}$ [IQR 40] versus clerks at $60 \mathrm{~mm}$ [IQR 45], $p<0.001$; Figure 1B). However, all students were less comfortable with treating pediatric pain, as reflected by $83.6 \%$ pre-clerks stating they were "uncomfortable" versus $52.1 \%$ of clerks (Figure 1B). Overall, there was no significant association between sex and level of comfort in adult $(p=0.79)$ or pediatric $(p=0.87)$ pain management.

The comfort levels of clerks and pre-clerks in prescribing oral acetaminophen, oral ibuprofen, intravenous morphine, and oral codeine were approximately the same for both adults and pediatric patients (Figure 2 ). Clerks $(n=26)$ were, however, more comfortable with prescribing oxycodone in adults (median $47 \mathrm{~mm}$ [IQR 51] versus pre-clerks $0 \mathrm{~mm}$ [IQR 11]), but there were not enough respondents $(n=1)$ to draw conclusions regarding oxycodone in pediatric patients.

For dosage questions in the adult scenarios, a correct dose of oral acetaminophen was defined as any value between 650 and $1000 \mathrm{mg}$, oral ibuprofen as any value between 400 and $800 \mathrm{mg}$, and intravenous morphine as any value between 2.5 and $5 \mathrm{mg}$. For the pediatric scenarios, a correct dose of oral acetaminophen was defined as any value between 10 and 15 $\mathrm{mg} / \mathrm{kg}$, oral ibuprofen as any value between 5 and $10 \mathrm{mg} /$ $\mathrm{kg}$, and intravenous morphine as any value between 0.05 and $0.1 \mathrm{mg} / \mathrm{kg}$. All dose recommendations were obtained from Lexicomp. ${ }^{24}$ Pediatric scenarios were based on an otherwise healthy $10 \mathrm{~kg}$ child, and adult scenarios were based 
A

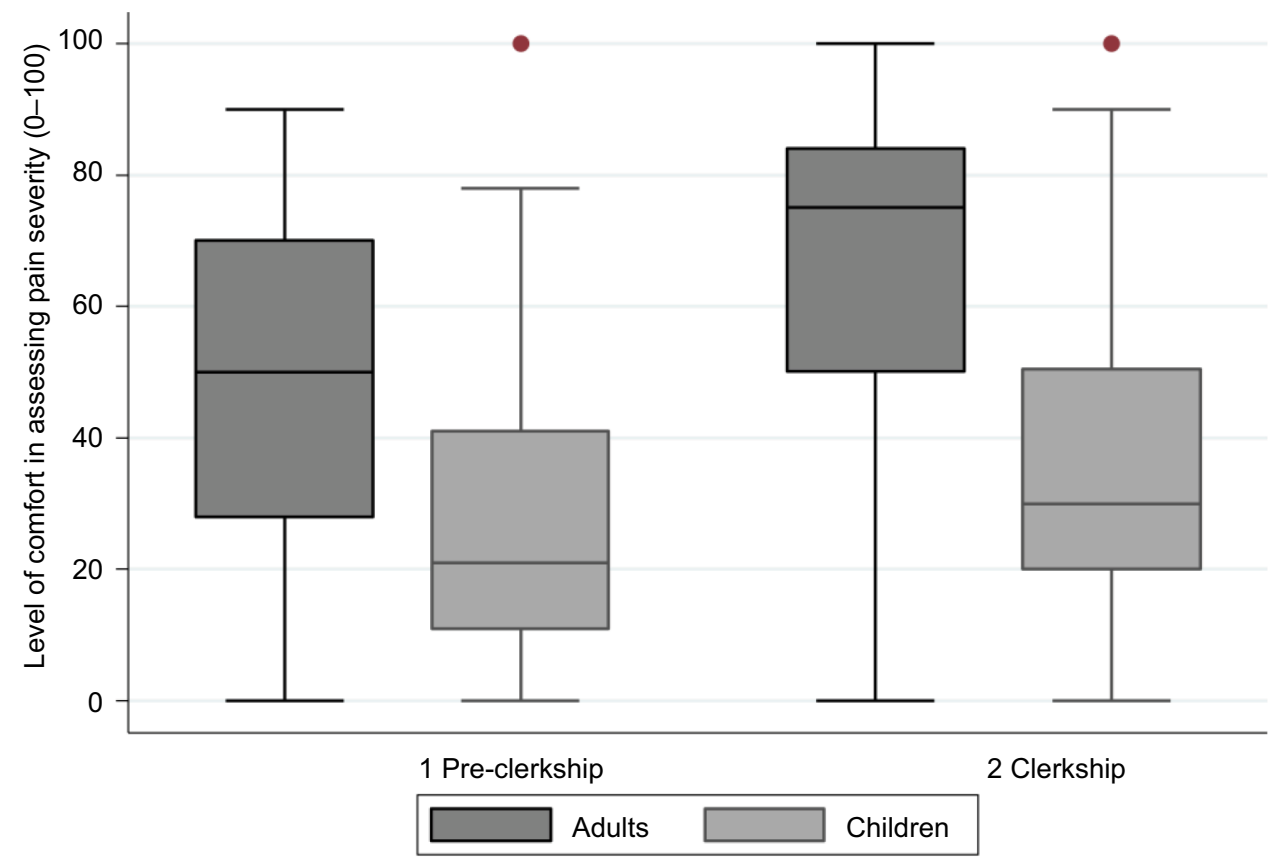

B

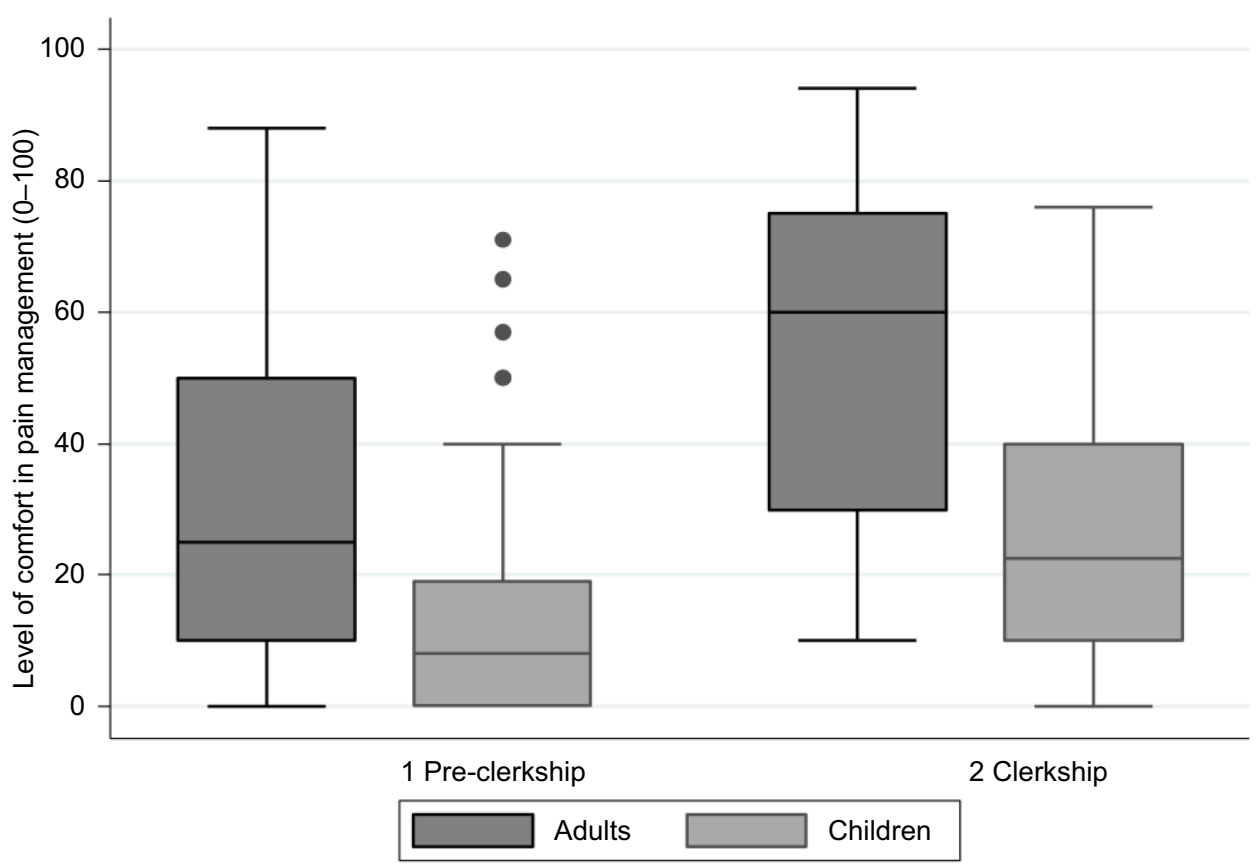

Figure I Medical students' reported degree of comfort in assessing and managing pain in adult and pediatric patients.

Notes: (A) Level of comfort in assessing pain severity and (B) level of comfort in pain management; $(n=73$ for pre-clerks, $n=48$ for clerks, $p<0.00 \mathrm{I}$ ).

on an otherwise healthy $75 \mathrm{~kg}$ adult. Remarkably, $54.2 \%$, $39.6 \%$, and $56.2 \%$ of clerks reported incorrect doses of acetaminophen, ibuprofen, and morphine, respectively, for adults (Figure 3). For children, 54.2\%, 54.2\%, and 78.7\% of clerks reported incorrect doses for these same medications (Figure 3).

\section{Attitudes}

Pain management myths and facts

On a five-point Likert scale, clerks and pre-clerks were asked to indicate their thoughts on certain pain management myths and facts. Clerks and pre-clerks responded similarly to most statements. However, more pre-clerks than clerks thought 


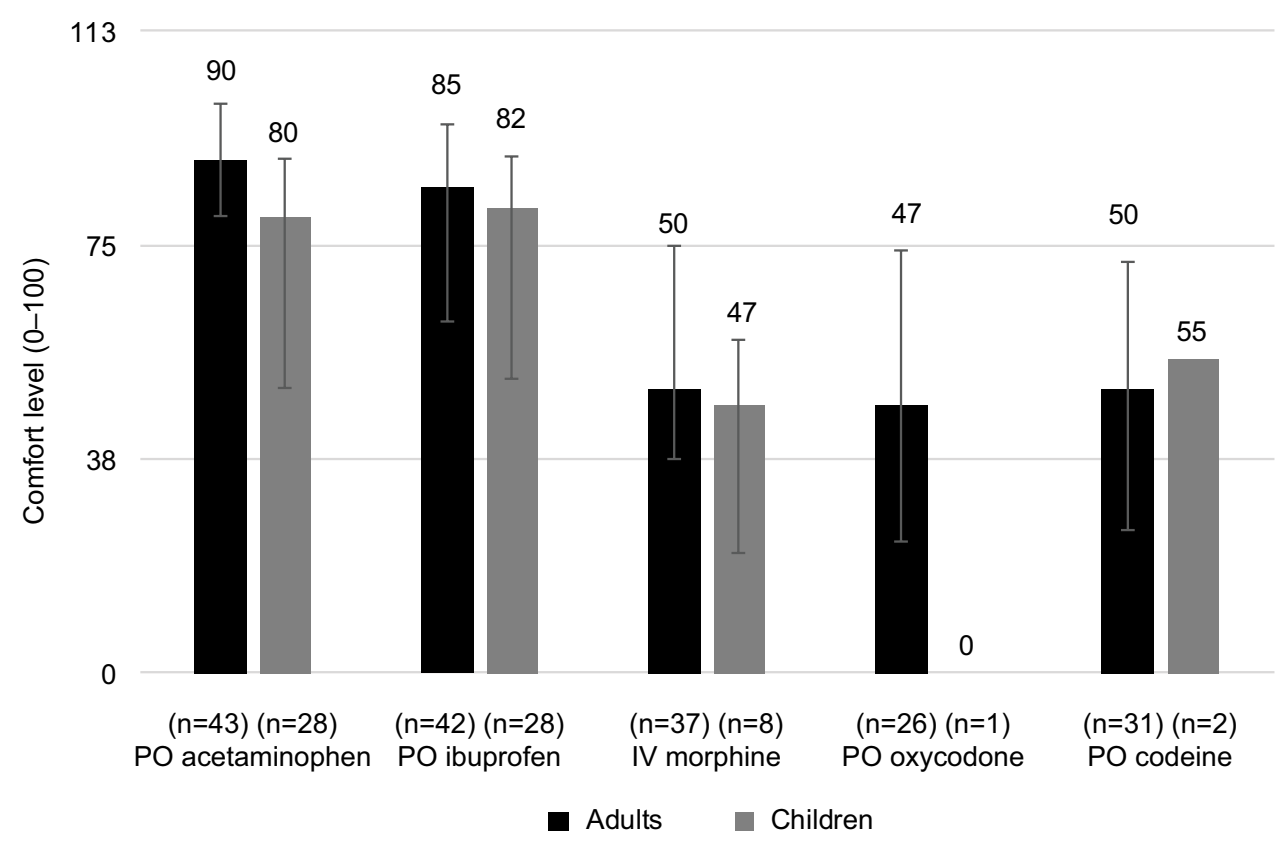

Figure 2 Clerkship students' level of comfort with prescribing common pain medications to adult and pediatric populations. Abbreviations: IV, intravenous; $\mathrm{PO}$, per os.

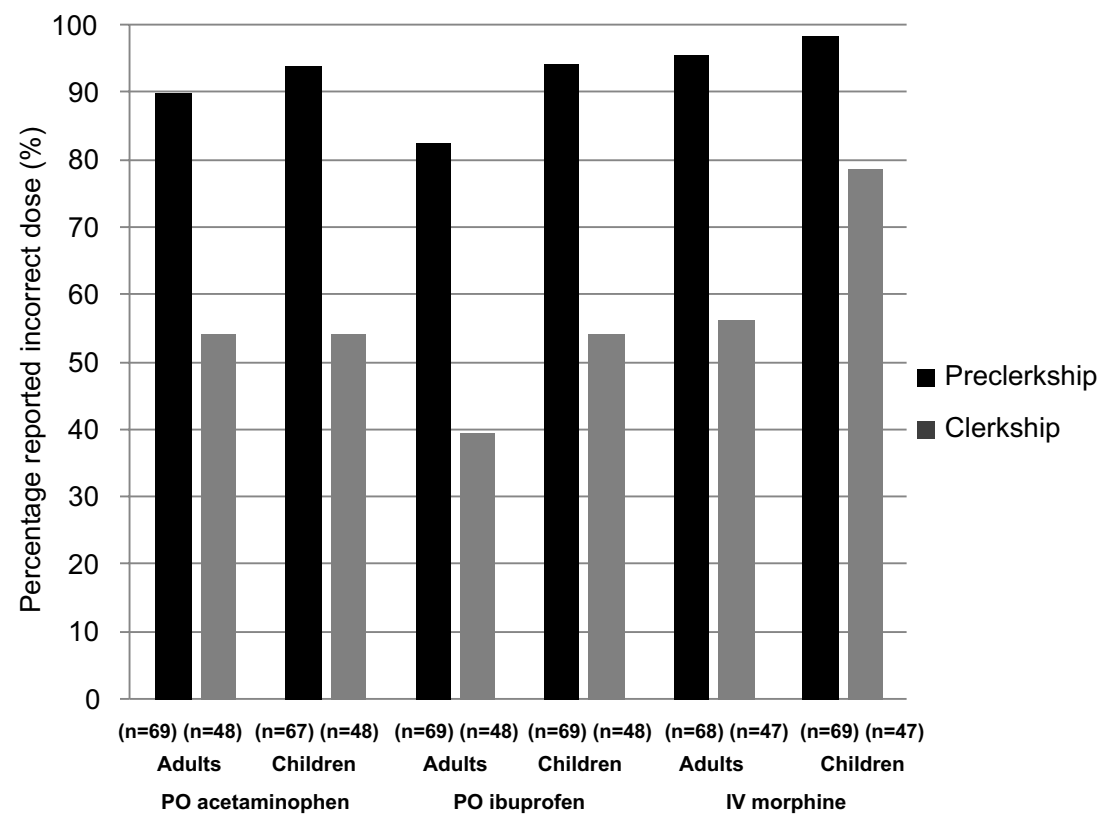

Figure 3 Proportion of respondents in pre-clerkship and clerkship reporting the incorrect dose of common pain medications for adult versus pediatric patients. Abbreviations: IV, intravenous; PO, per os.

that pain treatment could mask an underlying diagnosis and that risk or concern for opioid dependence was a reason not to prescribe analgesia to children. Full results are shown in Table 3.

\section{Barriers and facilitators}

Students identified that the top barriers to adequate pain management in adults were: 1) drug adverse events and contraindications, 2) fear of addictions/dependencies/tolerance, and
3) insufficient physician training. Top reported facilitators were: 1) good patient-physician communication, 2) physician education, and 3) involvement of multidisciplinary team (Table 4). For optimal pediatric pain management, the barriers were: 1) insufficient physician training, 2) communication barriers, and 3) drug adverse effects and contraindications. Facilitators to optimal pediatric pain management were: 1) physician/parental education, 2) health care team/parental support, and 3) good communication (Table 4). 
Table 3 Students' perception of pain management myths and facts $(n=117)^{\mathrm{a}}$

\begin{tabular}{|c|c|c|c|c|}
\hline \multirow[t]{2}{*}{ Statement } & \multicolumn{2}{|c|}{ Pre-clerkship, $n$ (\%), n=68 } & \multicolumn{2}{|c|}{ Clerkship, $n$ (\%), n=48 } \\
\hline & Agree & Disagree & Agree & Disagree \\
\hline Children require less analgesia than adults due to their immature neurologic systems & $4(5.9)$ & $50(73.5)$ & $21(43.8)$ & $17(35.4)$ \\
\hline Children require less analgesia than adults as they will not remember the pain & $\mathrm{I}(\mathrm{I} .5)$ & $61(89.7)$ & $0(0)$ & $45(93.8)$ \\
\hline A concern for opioid dependency is a reason not to prescribe analgesia to children & II (32.4) & $40(58.8)$ & $I(2.1)$ & $4 \mathrm{I}(85.4)$ \\
\hline Children are at higher risk of oversedation from analgesia than adults & $39(57.4)$ & $5(7.4)$ & $21(43.8)$ & $7(14.6)$ \\
\hline Pain scores can help measure pain for children & $46(66.7)$ & $7(10.1)$ & $34(72.3)$ & $3(6.4)$ \\
\hline Pain scores of 4 or more (out of 10 ) should be treated & $44(63.8)$ & $2(2.9)$ & $36(75)$ & $2(4.2)$ \\
\hline Pain medications can mask underlying problems or the "true diagnosis" & $37(53.6)$ & $13(18.8)$ & $10(20.8)$ & $29(60.4)$ \\
\hline $\begin{array}{l}\text { Using pain medications after painful injuries can help get children back to normal } \\
\text { activities quicker }\end{array}$ & $47(68.1)$ & $6(8.7)$ & $38(79.2)$ & $2(4.2)$ \\
\hline Pain medications help children heal better & $27(39.1)$ & $8(11.6)$ & $20(42.6)$ & $7(14.9)$ \\
\hline Pain medications are the only way to effectively treat pain & $0(0)$ & $62(89.9)$ & $I(2 . I)$ & $42(89.4)$ \\
\hline
\end{tabular}

Note: answered as per a five-point Likert scale from strongly disagree to strongly agree; responses were then grouped into three categories: agree, disagree, or neither agree nor disagree.

Table 4 Top five barriers and facilitators to optimal pain management

\begin{tabular}{|c|c|}
\hline $\begin{array}{l}\text { Barriers to optimal pain management in } \\
\text { adults }\end{array}$ & $\begin{array}{l}\text { Frequency (\%), } \\
\mathrm{n}=99\end{array}$ \\
\hline Drug adverse effects and contraindications & $44(16.3)$ \\
\hline Fear of addictions/dependencies/tolerance & $38(14.1)$ \\
\hline Insufficient physician training & $22(8.1)$ \\
\hline Health care provider biases & $21(7.8)$ \\
\hline Patient comorbidities and history of chronic pain & $20(7.4)$ \\
\hline $\begin{array}{l}\text { Facilitators to optimal pain management in } \\
\text { adults }\end{array}$ & $\begin{array}{l}\text { Frequency (\%), } \\
\mathrm{n}=76\end{array}$ \\
\hline Good patient-physician communication & $30(28.0)$ \\
\hline Physician education & $20(18.7)$ \\
\hline Involvement of multidisciplinary team & $10(9.35)$ \\
\hline Good reassessments & $7(6.54)$ \\
\hline Patient history utilization & $6(5.61)$ \\
\hline $\begin{array}{l}\text { Barriers to optimal pain management in } \\
\text { children }\end{array}$ & $\begin{array}{l}\text { Frequency (\%), } \\
\mathrm{n}=100\end{array}$ \\
\hline Insufficient physician training & $60(31.4)$ \\
\hline Communication barriers & $29(15.2)$ \\
\hline Drug adverse effects and contraindications & $22(11.5)$ \\
\hline Parental reluctance/lack of education & $21(11.0)$ \\
\hline Fear of addictions/dependencies & $13(6.8)$ \\
\hline $\begin{array}{l}\text { Facilitators to optimal pain management in } \\
\text { children }\end{array}$ & $\begin{array}{l}\text { Frequency (\%), } \\
\mathrm{n}=7 \mathbf{1}\end{array}$ \\
\hline Physician/parental education & $16(20.5)$ \\
\hline Health care team/parental support & $14(17.9)$ \\
\hline Good communication & $13(16.7)$ \\
\hline Pain score objectivity & $7(8.97)$ \\
\hline Involvement of multidisciplinary team & $5(6.4 I)$ \\
\hline
\end{tabular}

Note: Multiple responses were permitted.

\section{University of Alberta curriculum map}

A curriculum map from the Faculty of Undergraduate Medical Education at the University of Alberta was performed as of March 2015. This revealed that pre-clerkship students
Table 5 University of Alberta pain curriculum

\begin{tabular}{llllll}
\hline Hours of teaching & \multicolumn{2}{l}{ Pre-clerkship } & & \multicolumn{2}{l}{ Clerkship } \\
\cline { 2 - 3 } \cline { 6 - 7 } \cline { 5 - 6 } & Year I & Year 2 & & Year 3 & Year 4 \\
\hline Lecture hours (hours) & 5 & 19 & & 4 \\
Small group hours (hours) & 6 & 24 & & 0 & 18 \\
Total & II & 43 & 4 & 22 \\
\hline
\end{tabular}

received a total of 54 hours of education on topics related to pain, with sessions provided as either 1-hour lectures or 2-hour small group discussions. In total, there were 23 lecture hours and 30 small group hours (Table 5). Of these, only 1 hour of lecture was noted to contain pediatric pain content. The report further showed that the clerkship curriculum consisted of 8 hours of lectures and 18 hours of small group sessions containing pain content during clerkship.

\section{Discussion}

In this survey of undergraduate medical students from the University of Alberta, Canada, we found students recalled, at the most, 7 hours of formal education on pain management in either pre-clerkship or clerkship, and they reported that it had been primarily delivered in didactic formats. Clerkship students were more comfortable with managing and assessing pain than pre-clerkship students, indicating that clinical experience and education received during this time did positively influence medical students' knowledge of pain management. However, both groups were uncomfortable with management of pain in children. Overall, correct dosing of common analgesics for adults by clerkship students was poor, and accuracy worsened when dosing medications for children. 
Consensus among students was that pain management is important but teaching on this topic was not prioritized in their medical curriculum. Survey respondents recalled $<5$ hours of teaching on pain management in their previous school year when curriculum mapping showed they, in fact, received up to 54 hours in pre-clerkship and 26 hours during clerkship. Coverage for pediatric pain was variable and consisted of simulations or isolated learning opportunities during pediatric medicine rotations. Teaching sessions were mainly focused on the anatomy of pain structures and assessment of conditions that cause acute or chronic pain. Little emphasis was placed on the practical assessment and treatment of acute pain. Additionally, a large part of this curriculum was dedicated toward treating the conditions associated with pain rather than directly about managing pain itself. Sessions on pain were also scattered throughout various blocks, which potentially affected students' perception of how little teaching they received, and made it difficult for them to recall targeted education on acute pain. Furthermore, pain teaching was not standardized for clerks, whose learning experiences vary depending on their assigned placements and preceptors as they are sent to different hospitals to gain more clinical exposure. These factors could contribute to how much clerks can recall about pain management.

Our findings were in line with a Canada-wide study that showed two-thirds of medical schools could not identify any pain education in their curriculum. ${ }^{25}$ However, our findings differed from American programs that reported formal pain education curricula. For example, at the University of Washington School of Medicine, there were 25 hours of mandatory teaching. It has been previously shown that medical students of all ages have significant "opiophobia" (an unwillingness to prescribe opioids for fear of patient addiction or legal sanctions), and that personality traits and desired postgraduate specialty influence this phobia. ${ }^{26}$ Introducing a formal pain curriculum is a potential solution to train physicians with knowledge and comfort with acute pain management. In fact, in 2012, Germany introduced pain management as a mandatory subject in medical school to prioritize knowledge of this important issue. ${ }^{27}$ Other schools that have instituted similar mandatory programs hope that more training will "increase knowledge and competency in biopsychosocial measurement-based pain narrative and risk assessment, improve understanding of persistent pain as a chronic complex condition, and expand the role of patientcentered inter-professional treatment for medical students, residents, and fellows, leading to better prepared practicing physicians". ${ }^{28}$
Survey respondents recalled their teaching primarily in didactic format; however, most students indicated small group and bedside teaching methods would be more effective. Previous studies, including a systematic review, have shown that non-didactic formats, such as web-based modules and small group problem-based learning, or case-based discussions were effective at improving pain management outcomes such as knowledge, confidence, attitudes, self-confidence, and patient care. ${ }^{13,14,17,29}$ Given the desire of students to receive teaching in non-lecture format, and the evidence of improved knowledge uptake, we advocate for the pain management curriculum to be delivered in formats such as small group, online modules, and bedside teaching.

Across all years, students were uncomfortable in both managing and assessing pain in children. This is consistent with previous literature that showed poor pre-intervention scores on knowledge tests. ${ }^{13,14}$ These studies demonstrated improvement with interventions such as web-based modules and problem-based learning. Interestingly, Ameringer et al showed that confidence in assessing pediatric pain improved from only $6 \%$ to $25 \%$ following an online module; still, most students $(71 \%)$ said they intend to make positive changes to their practice based on the module. ${ }^{14}$ We also know from previous studies that pediatric pain management in practice is often suboptimal; ${ }^{13}$ this is supported by findings from mapping the current medical undergraduate curriculum, which showed that pediatric pain teaching was limited to just 1 hour of lecture time during pre-clerkship.

The dosing accuracy of medical students for both adult and pediatric patients was very poor, even for common medications such as ibuprofen and acetaminophen. Further, these students, who incorrectly dosed acetaminophen and ibuprofen $50 \%-95 \%$ of the time, indicated very high (80-90 $\mathrm{mm}$ ) comfort with dosing these same medications. This suggests medication dosage teaching is not well retained by students, and that their comfort and confidence in dosing these medications is incongruent with their demonstrated capacity to do so in hypothetical scenarios. A recent survey of newly graduated Irish medical students agreed with this, finding $89 \%$ felt confident in prescription writing, but only $58 \%$ in drug dose calculations; only $28 \%$ agreed that their medical education had prepared them for prescribing medications. ${ }^{30}$ Dosing accuracy and retention should be important aspects of the undergraduate pain management curriculum. Overall, this survey has revealed that students recognize the importance of adequate analgesia and want pain education prioritized using teaching modalities that best suit their learning needs. 


\section{Limitations and future directions}

Limitations of this study included a low response rate, recall bias, and the fact that respondents were from a single medical school in Canada. The low response rate was likely due to non-ideal timing of survey distribution. The survey was sent out near the end of the school year and many students were either occupied by final exams or were on vacation. Furthermore, this study was performed at a single university, and thus was not necessarily generalizable to other medical schools. We do feel, however, that the students' identification of barriers and facilitators, preferred teaching modality, agreement with myths/facts, and pre-clerkship students' comfort with assessing and managing acute pain will be relevant to other medical schools.

To improve the response rates, we could have distributed the survey earlier in the year to avoid exam and vacation time and to give us the opportunity to talk to students directly in class to offer them the option of filling out paper surveys. Small gifts could also have been used as incentives for completing the survey. Another future direction for this study would be to perform a faculty survey to gather responses from curriculum planners and course coordinators who design and execute courses. The aim would be to evaluate their thoughts on the current pain curriculum and query their expertise on potential improvement strategies. It would also be relevant to distribute the same surveys to faculty and students from other medical schools in Canada.

\section{Conclusion}

Students reported that education about pain assessment and management was very important to acquire in undergraduate medical training. However, they felt that this perceived importance was not reflected in their actual medical curriculum. Further, when assessing their knowledge of commonly used analgesics, students failed to demonstrate an ability to safely dose these medications. Students reported even greater discomfort when assessing and treating children. Educational strategies are required to address student-identified challenges in the current pain curriculum, which include higher prioritization and hours devoted to pain management instruction, emphasis on pediatric patients, and teaching in non-didactic formats. With suggested curriculum changes, undergraduate medical programs could ensure that future physicians will receive adequate training in pain management, which would ideally result in better patient care.

\section{Acknowledgments}

We would like to express our sincere gratitude toward all the volunteers who have helped to assess and pilot our study tool.
We greatly appreciate the research coordinator assistance that Ms Nadia Dow and Ms Manasi Rajagopal have provided to this study. We would also like to thank Mr Mikus Lorenc, Ms Leyla Sekyi, and Ms Patricia Nakatanai for their help in survey programming and distribution, and lastly, all members of medical classes 2016-2019 from the University of Alberta, Edmonton, for their participation in our study.

\section{Disclosure}

The authors report no conflicts of interest in this work.

\section{References}

1. Sinatra R. Causes and consequences of inadequate management of acute pain. Pain Med. 2010;11(12):1859-1871.

2. Curry SL, Russ SW. Identifying coping strategies in children. J Clin Child Psych. 1985;14(1):61-69.

3. Megel ME, Houser CW, Gleaves LS. Children's responses to immunizations: lullabies as a distraction. Issues Compr Pediatr Nurs. 1998;21(3):129-145.

4. Pate JT, Blount RL, Cohen LL, Smith AJ. Childhood medical experience and temperament as predictors of adult functioning in medical situations. Child Health Care. 1996;25(4):281-298.

5. Weisman SJ, Bernstein B, Schechter NL. Consequences of inadequate analgesia during painful procedures in children. Arch Pediatr Adolesc Med. 1998;152(2):147-149.

6. Grunau RE. Neonatal pain in very preterm infants: long-term effects on brain, neurodevelopment and pain reactivity. Rambam Maimonides Med J. 2013;4(4):e0025.

7. World Health Organization. WHO Guidelines on the Pharmacological Treatment of Persisting Pain in Children with Medical Illnesses. Geneva: World Health Organization; 2012.

8. Wilson JE, Pendleton JM. Oligoanalgesia in the emergency department. Am J Emerg Med. 1989;7(6):620-623.

9. Todd KH, Ducharme J, Choiniere M, et al. Pain in the emergency department: results of the pain and emergency medicine initiative (PEMI) multicenter study. J Pain. 2007;8(6):460-466.

10. Birnie KA, Chambers CT, Fernandez CV, et al. Hospitalized children continue to report undertreated and preventable pain. Pain Res Manag 2014;19(4):198-204.

11. Alexander J, Manno M. Underuse of analgesia in very young pediatric patients with isolated painful injuries. Ann Emerg Med. 2003;41(5): 617-622.

12. Lewis LM, Lasater LC, Brooks CB. Are emergency physicians too stingy with analgesics? South Med J. 1994;87(1):7-9.

13. Cohen IT, Bennett L. Introducing medical students to paediatric pain management. Med Educ. 2006;40(5):476.

14. Ameringer S, Fisher D, Sreedhar S, Ketchum JM, Yanni L. Pediatric pain management education in medical students: impact of a web-based module. J Palliat Med. 2012;15(9):978-983.

15. Adam R, Bond C, Murchie P. Educational interventions for cancer pain. A systematic review of systematic reviews with nested narrative review of randomized controlled trials. Patient Educ Couns 2015;98(3):269-282.

16. Mezei L, Murinson BB, Johns Hopkins Pain Curriculum Development T. Pain education in North American medical schools. J Pain. 2011;12(12):1199-1208.

17. Maclaren JE, Cohen LL. Teaching behavioral pain management to healthcare professionals: a systematic review of research in training programs. J Pain. 2005;6(8):481-92.

18. Tellier PP, Belanger E, Rodriguez C, Ware MA, Posel N. Improving undergraduate medical education about pain assessment and management: a qualitative descriptive study of stakeholders' perceptions. Pain Res Manag. 2013;18(5):259-265. 
19. Kircher J, Drendel AL, Newton AS, Dulai S, Vandermeer B, Ali S. Pediatric musculoskeletal pain in the emergency department: a medical record review of practice variation. CJEM. 2014;16(6):449-457.

20. Washington DC: 2018 International Association for the Study of Pain. 2018; Available from: https://http://www.iasp-pain.org/ GlobalYear?navItemNumber=580. Accessed March 13, 2018.

21. Dillman DA SJ, Christian LM. Internet, Mail, and Mixed-Mode Surveys: The Tailored Design Method. Hoboken, NJ: Wiley; 2009.

22. Ung A, Salamonson Y, Hu W, Gallego G. Assessing knowledge, perceptions and attitudes to pain management among medical and nursing students: a review of the literature. Br J Pain. 2016;10(1): $8-21$.

23. Burns KE, Duffett M, Kho ME, et al. A guide for the design and conduct of self-administered surveys of clinicians. CMAJ. 2008;179(3): $245-252$.

24. Lexi-Drugs ${ }^{\circledR} .2016$. Available from: http://www.wolterskluwercdi.com/ lexicomp-online/. Accessed March 13, 2018.
25. Watt-Watson J, McGillion M, Hunter J, et al. A survey of prelicensure pain curricula in health science faculties in Canadian universities. Pain Res Manag. 2009;14:439-444.

26. Weinstein SM, Laux LF, Thornby JI, et al. Medical students' attitudes toward pain and the use of opioid analgesics: implications for changing medical school curriculum. South Med J. 2000;93:472-478.

27. Kopf A, Dusch M, Alt-Epping B, Petzke F, Treede RD. [Pain medicine as a cross-sectional subject in German medical schools. An opportunity for general pain management]. Schmerz. 2014;28(4):405-413. German.

28. Tauben DJ, Loeser JD. Pain education at the University of Washington School of Medicine. J Pain. 2013;14(5):431-437.

29. Paneduro D, Pink LR, Smith AJ, et al. Development, implementation and evaluation of a pain management and palliative care educational seminar for medical students. Pain Res Manag. 2014;19(5):230-234.

30. Geoghegan SE, Clarke E, Byrne D, et al. Preparedness of newly qualified doctors in Ireland for prescribing in clinical practice. Br J Clin Pharmacol. 2017;83(8):1826-1834.
Journal of Pain Research

\section{Publish your work in this journal}

The Journal of Pain Research is an international, peer reviewed, open access, online journal that welcomes laboratory and clinical findings in the fields of pain research and the prevention and management of pain. Original research, reviews, symposium reports, hypothesis formation and commentaries are all considered for publication.

\section{Dovepress}

The manuscript management system is completely online and includes a very quick and fair peer-review system, which is all easy to use. Visit http://www.dovepress.com/testimonials.php to read real quotes from published authors. 